\title{
PROGRAMAS DE REGULARIZAÇÃO FUNDIÁRIA SUSTENTÁVEL: A QUESTÃO DAS VULNERABILIDADES SOCIOAMBIENTAIS EM ASSENTAMENTOS PRECÁRIOS CONSOLIDADOS EM ÁREAS DE PRESERVAÇÃO PERMANENTE
}

\section{Jeane Aparecida Rombi de Godoy Rosin ${ }^{1}$}

Angélica T. Benatti Alvim²

RESUMO: Este artigo tem por objetivo desenvolver reflexões sobre a sustentabilidade de políticas públicas de regularização fundiária, tendo como base analítica a problemática socioambiental oriunda da ocupação e uso do espaço urbano em APP - Áreas de Preservação Permanente. Nesse sentido, a discussão a ser desenvolvida tem como foco a questão dos processos precários de assentamentos humanos estabelecidos em APP urbanas inseridas em regiões metropolitanas, por grupos sociais de menor renda ou sem renda. Desse modo, tem-se como a preocupação fundamental a complexa questão da informalidade, buscando enfocar a verdadeira proporção dos impactos ambientais, da precariedade urbana e da vulnerabilidade, que ao longo de décadas, aflige um universo crescente de vidas humanas. Assim, em meio a uma série de questionamentos de ordem jurídica, urbanística e ambiental relativos a implementação dos Programas de Regularização Fundiária em áreas de vulnerabilidades ambientais, considerando que este quadro tem-se agravado frente à ocorrência crescente de acidentes ambientais em diversas cidades no país. Desse modo, ao considerar que, os assentamentos precários em APP estão estritamente relacionados à dinâmica da produção do espaço urbano, onde sua interface econômica (mercado de terras), social (segregação sócio espacial e vulnerabilidade social) e ambiental (riscos e impactos ambientais), poderão

\footnotetext{
${ }^{1}$ Doutorando no Programa de Pós-Graduação em Arquitetura e Urbanismo na Universidade Presbiteriana Mackenzie/SP, Bolsista CAPES/Prosup. E-mail: jeanerosin@terra.com.br

${ }^{2}$ Arquiteta e urbanista; professora e coordenadora geral de Pós-Graduação Stricto Sensu da Universidade Presbiteriana Mackenzie; abalvim@mackenzie.br
} 
demonstrar ao longo desta pesquisa, a premência de adoção de novos paradigmas de planejamento e gestão das cidades, notadamente no que se refere aos novos princípios do Urbanismo Sustentável.

Palavras-chave: APPs Urbanas, Assentamentos Precários, Vulnerabilidades Socioambientais, Desastres Ambientais.

\section{INTRODUÇÃO}

O intenso processo de urbanização das cidades brasileira foi drasticamente marcado pela descontrolada ocupação informal de áreas de fragilidade ambiental, tais como: as áreas de preservação permanente, áreas de mananciais, áreas de encostas, áreas non-aedificandi, ou seja, áreas tuteladas pelo ordenamento jurídico em razão de seus valores ambientais. A ocorrência estrondosa dos processos de informalidade urbana, em áreas periféricas, assim como a intensa densificação dos assentamentos precários consolidados, é para alguns autores dentre eles, SMOLKA (2003, p.263), decorrentes não apenas do aumento absoluto e relativo de pobres urbanos, mas, sobretudo da "falta de programas habitacionais, da queda de investimentos públicos em equipamentos urbanos e serviços e do próprio esvaziamento do planejamento urbano", sem contar que "todos esses são fatores que, em última análise, incidem diretamente na oferta do solo urbanizado". Nesse sentido, é de fundamental importância considerar que, o acesso ao mercado regular de terras está diretamente vinculado ao poder de aquisição ou de compra da população, o que vem esclarecer o motivo pelo qual, milhares de famílias de menor poder aquisitivo, são circunstancialmente obrigadas a ocuparem de modo irregular áreas públicas ou privadas, muitas destas, impróprias à ocupação humana.

A partir deste contexto, os assentamentos precários localizados em áreas ambientalmente vulneráveis, passaram a se constituir num aspecto que vai muito além da delicada problemática urbana, tendo em vista a complexidade das questões de ordem jurídica, social, econômica, cultural, e principalmente urbanística, decorrentes da longa e vergonhosa ausência do Estado frente à questão. Todavia, em razão da dimensão e da gravidade com que essas tipologias aparecem nos cenários urbanos, tendo em vista, que parte considerável delas são instaladas em espaços legalmente protegidos, a questão que envolve os processos de 


\section{som

regularização fundiária em APP urbanas, tem de modo contundente, não apenas pautado os atuais debates nos mais diversos meios, como também, causado o despertar do Estado para o cumprimento de suas responsabilidades constitucionais relacionadas à efetivação do Direito à Cidade.

Neste sentido, a percepção da questão urbana envolve necessariamente diversos aspectos, que se manifestam em escalas e contextos diferenciados, porém correlacionados, como a exclusão social, a segregação espacial, o desemprego, a violência, a interferência do capital imobiliário nos processos de gestão urbana, e a degradação do meio natural, dentre tantos outros. Com efeito, tornou-se inquestionável, que o quadro de precariedades decorrentes desses aspectos foi produzido ao longo do processo de urbanização do país, permanecendo por muito tempo negligenciado, e que em razão de seus efeitos nefastos, vem ao longo das décadas comprometendo o desenvolvimento do país, e agora de modo irrefutável, está à exigir do Estado o inadiável cumprimento de suas responsabilidades à luz do princípio da eficiência.

A literatura mostra que, ao longo do século XX, ocorreu um significativo desacerto relacionado à ordem jurídica em vigor e aos processos de produção não somente em cidades da América Latina como principalmente em cidades brasileiras. No Brasil, a partir da promulgação da Constituição Federal de 1988, com a incorporação de um capítulo referente à política urbana, há o reconhecimento de sua notória importância para a ordem jurídica do país ao reconhecer a consolidação de seu processo de urbanização, pois segundo Edésio Fernandes (2006, p.7) esta relevância se deu ao admitir essencialmente que, "as formas de organização socioeconômica e político-territorial do país eram de outra ordem que não aquelas reconhecidas pelo Código Civil de 1916". Entretanto, somente após dez anos, esse capítulo é regulamentado por meio da Lei Federal no.10.257/2001, denominada - Estatuto da Cidade, aprovada com a finalidade de consolidar a nova ordem jurídico-urbanística ao incorporar em seu arcabouço a Regularização Fundiária não apenas com a finalidade de amenizar os longos anos de omissão do Estado frente ao crescente processo de informalidade urbana, mas como diretriz de uma nova política urbana. Todavia quando esses processos de regularização incidem em áreas de fragilidade ambiental - as denominadas APP urbanas, a literatura relacionada ao tema, leva a concluir que se faz necessário ter muita atenção e prudência, em razão de sua própria natureza estas áreas são impróprias para a ocupação humana, tendo em vista sua constituição geomorfológica, como também a importância das funções ambientais que desempenham para o equilíbrio do meio 
ambiente urbano. Outro ponto de extrema relevância a ser considerado, diz respeito à vulnerabilidade dessas áreas à ocorrência de desastres ambientais.

Desse modo, os programas de regularização fundiária como instrumento jurídico, são para muitos especialistas na matéria, dentre eles, Edésio Fernandes e Betânia Afonsin, (2003), uma conquista social, pois abriram a possibilidade de todos aqueles que foram oprimidos pelo sistema capitalista, de encontrar na informalidade dos loteamentos clandestinos a possibilidade de validar seu direito a moradia. Neste sentido, esta reflexão reconhece a necessidade de elaboração de políticas públicas com o intuito de promover a inclusão sócio-espacial por meio dos programas de urbanização e da regularização fundiária sustentável em assentamentos precários.

Em boa parte das cidades no Brasil, muitos são os fatores que provocaram a ocorrência de assentamentos precários em áreas de vulnerabilidade ambiental - as APPs, entre os quais são evidenciados a carência habitacional, disponibilidade de espaços com restrição ambiental, desrespeito as normas ambientais e urbanísticas, a ausência de fiscalização dos órgãos responsáveis, a inescrupulosa especulação imobiliária e, sobretudo o descaso do poder público.

No âmbito da questão, Rolnik (1997) alerta que a cidade ilegal (loteamentos informais, clandestinos e irregulares) é "tolerada para poder ser, posteriormente, negociada pelo Estado" através da regularização fundiária, como condicionante de um pacto entre Estado e as lideranças dos bairros, onde o Estado é tido como o "provedor" e os moradores da cidade ilegal passam a serem os "devedores de um favor do Estado". Neste contexto, a incorporação da cidade ilegal pela cidade legal (formal e oficial) ocorre como uma forma de anistia, através da regularização fundiária, favorecendo a implementação de uma política com fins explicitamente eleitorais. Entretanto, entende-se que o Direito à Cidade só será efetivado quando o Estado adotar uma política habitacional inclusiva, que não seja sinônima de uma barganha de escrituras pelos tão disputados votos.

Neste contexto, a instituição dos novos mecanismos jurídicos, tais como, o Estatuto da Cidade, a atual Resolução do CONAMA n 369 e a nova proposta de revisão da Lei Federal de Parcelamento do Solo - projeto de Lei 3057/00, denominada Lei de Responsabilidade Territorial, os processos de Regularização Fundiária adquiriram condições de efetividade, mesmo considerando que, muitas das ocupações ilegais quer estejam parcial ou totalmente instaladas em APPs, em função da vulnerabilidade geofísica não poderiam ser regularizadas 


\section{stom

nestas localidades, pois segundo Chaer(2007, p.91) "a solução habitacional de alguns não pode se sobrepor ao acesso ao meio natural equilibrado como direito de todos". Dessa forma, a complexidade do quadro em questão, necessita de uma atenção especial, pois ao se permitir a permanência da população instalada nestes locais de vulnerabilidade ambiental - identificados como áreas de riscos - estarão permitindo não apenas a violação do direito do acesso ao meio ambiente equilibrado, mas principalmente, a violação do mais sacrossanto dos direitos que é a preservação da vida.

No âmbito da questão, embora já seja previsto dentro dos procedimentos metodológicos que compõem os programas de regularização fundiária (editado pelo Ministério das Cidades) a elaboração do Plano de Risco, para locais que apresentem essas especificidades, muitas das ações definidas nesses processos, buscam alternativas para minimizar ou eliminar os riscos para a população residente, mas infelizmente em boa parte das intervenções realizadas, não tem ocorrido a identificação das situações de riscos para o meio natural, ou os riscos ambientais que poderiam afetar drasticamente não apenas o meio ambiente, mas por em risco inúmeras vidas, a exemplo do que tem ocorrido com diversas cidades recentemente no país.

A partir desse enfoque, é preciso considerar que a flexibilização dos parâmetros e limites de preservação em APP urbana, permitiram que em todo o território brasileiro, fosse fragilizada a prioridade de proteção e conservação das margens de rios, nascentes, mangues, dunas, encostas, topos de morro, assim como, os demais espaços de valores ambientais significativos considerados essenciais na realização de suas funções ambientais para a manutenção do equilíbrio dos ecossistemas urbanos.

Desse modo, a resolução 369/2006 do CONAMA, cujo objetivo primordial foi a viabilização dos processos de regularização fundiária em APPs, acabou por gerar muita discussão e divergências de opiniões entre ambientalistas e urbanistas, já que para os ambientalistas, essa nova resolução permite interpretações muito abrangentes no que se refere a questão de "utilidade pública" e "interesse social", por outro lado, os urbanistas vislumbraram grandes perspectivas para os conflitos fundiários urbanos.

$\mathrm{Na}$ realidade, a flexibilização ocorrida recentemente nas legislações federais, se constituíram antes de tudo, em novas possibilidades de planejamento para o poder público municipal. Todavia, mesmo considerando sua obrigatoriedade em efetivá-las, no caso das APPS urbanas, o quadro apresentado é bastante diferenciado e complexo - muitas foram 
dilapidadas pelo uso e ocupação inadequada e, em razão de sua importância relacionada aos diversos serviços ambientais que desempenham para o equilíbrio do ecossistema urbano, tornase de extrema relêvancia que essas limitações sejam revisadas em função das condições geomorfológicas de cada localidade, ou seja, as margens de proteção deveriam ser proporcionais a área territorial impermeabilizada, pois quanto mais impermeabilizado for o tecido urbano, maior será a necessidade de aumentar as áreas de proteção que podem desempenhar dentre as várias funções ambientais, a de absorção de água e reabastecimento do lençol freático.

Muitas cidades no país fizeram uso da engenharia de forma equivocada ao retificar os córregos, rios, não preservando as APPs, e hoje gastam somas exorbitantes na tentativa de corrigir os graves problemas decorrentes dessas medidas inadequadas e obsoletas, que têm ao longo dos anos, apresentado resultados sempre crescentes de inúmeros prejuízos tanto materiais, como principalmente ceifando vidas humanas. Frente a esse quadro, é de extrema importância a proposição de novos mecanismos jurídico-urbanísticos, bem como de práticas projetuais inovadoras potencializadas para o enfrentamento da questão. A partir desse contexto, o novo sistema jurídico e institucional que passa a reger as políticas urbanas em suas diversas faces, inclusive em ações de proteção ambiental, possibilita uma nova abordagem da questão dos assentamentos precários, tendo em vista sua grande incidência ocorrer em áreas de vulnerabilidade ambiental, protegidas tanto pela legislação federal como estadual.

\section{A INFORMALIDADE URBANA: O CONTEXTO DAS CIDADES NO BRASIL}

Em 2010, o Censo do IBGE, disponibilizado em 29/11/2010, informou que a população brasileira é composta por 190.732.694 habitantes, sendo que deste número 84,35\% são residentes de áreas urbanas, ou seja, o país deixou seu aspecto rural para assumir um perfil eminentemente urbano. Como resultados deste processo de transição surgem nas cidades, inúmeras demandas e graves questões, desencadeando uma série de reflexos e impactos negativos no equilíbrio ambiental e, sobretudo, no bem-estar da população. Nesse cenário, tornam-se evidentes os assentamentos precários, que diante do olhar complacente do poder público e da sociedade, passaram a compor a parte compreendida como cidade ilegal, ignorando todo o universo das normas urbanísticas vigentes. Nesse contexto, o processo de urbanização das cidades brasileiras, marcadas por assimetrias diversas decorrentes não apenas 


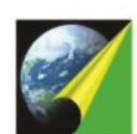

ANAP

da ação deletéria do mercado imobiliário como também da ausência de um planejamento apto em compreender a importância das dinâmicas dos ecossistemas, se constituíram nos gigantescos obstáculos que contribuíram não apenas para a degeneração dos habitats naturais, mas essencialmente para a desvalorização de suas imensas potencialidades.

A partir desse cenário, os efeitos decorrentes do intenso processo de crescimento urbano, aliados a uma arcaica sistemática de políticas públicas incipientes e desconexas, acabaram por assinalar as diferenças marcantes na paisagem das cidades, as quais encontram expressividade nos quadros crescentes de segregação e desigualdade socioespacial.

Com enfoque nesta problemática, várias pesquisas têm sido realizadas, tanto por academias conceituadas como por importantes instituições governamentais, Fernandes (2006, p.16), explica que "cerca de $40 \%$ das cidades brasileiras com menos de 20 mil habitantes possuem loteamentos clandestinos. Isso não é um mero sintoma de um modelo de desenvolvimento, mas o próprio modelo. Não estamos falando de uma exceção, mas da regra". Essa situação, teve significativo enfoque nos estudos realizados pelo Instituto de Pesquisa Econômica Aplicada - IPEA, ao apontar que em 2010, ainda há 50 milhões de brasileiros vivendo em condições precárias, como cortiços, sem teto, favelas e assentamentos irregulares. As figuras abaixo, foram inseridas em razão de apresentarem dados que podem subsidiar na compreensão da real complexidade do problema em discussão.

Tabela 01: Condições Urbanas - Brasil (2010)

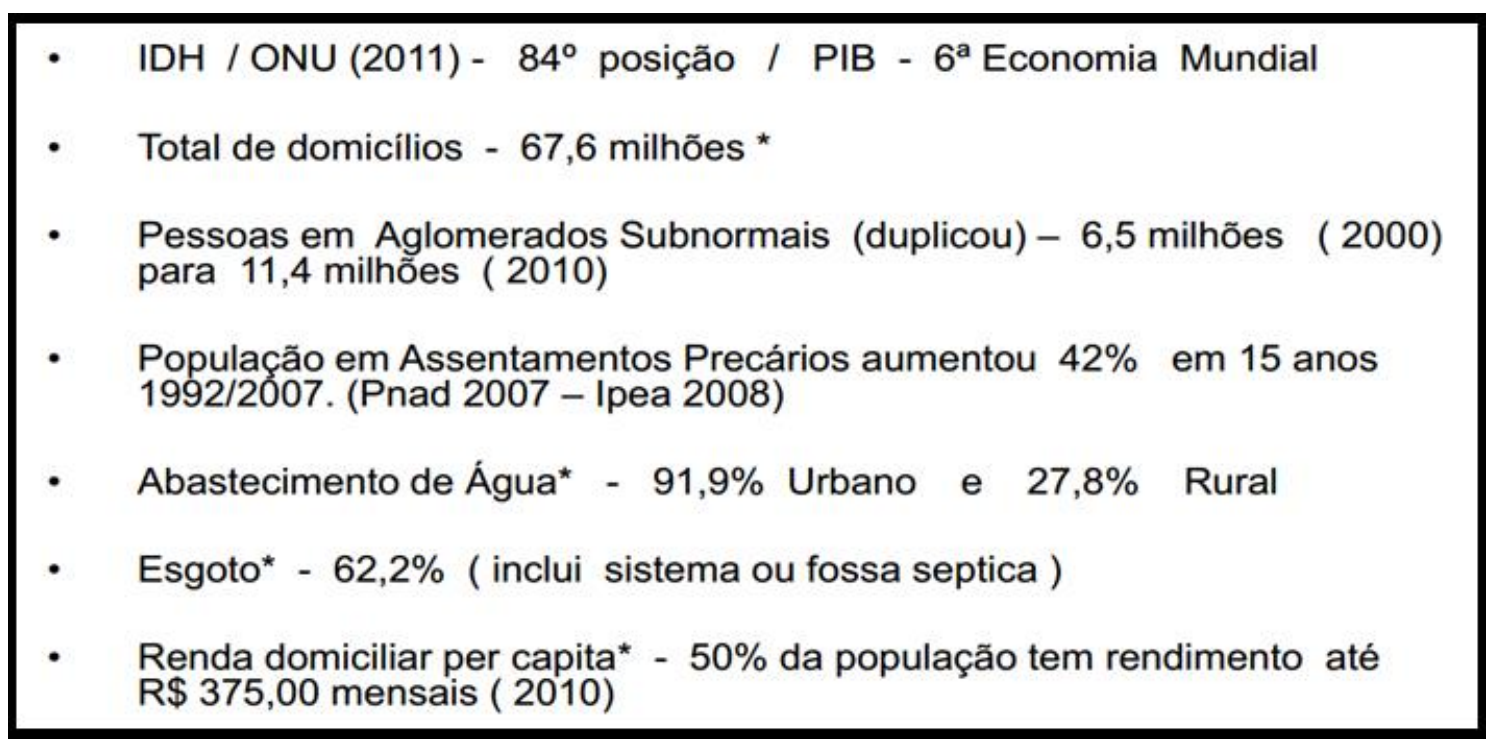

Fonte:http://www.cepal.org/ccas/noticias/paginas/1/49071/Mexico Diana Final 30-01 2013.pdf 
Gráfico 01 - Distribuição de setores em aglomerados subnormais, por grandes regiões - 2010.

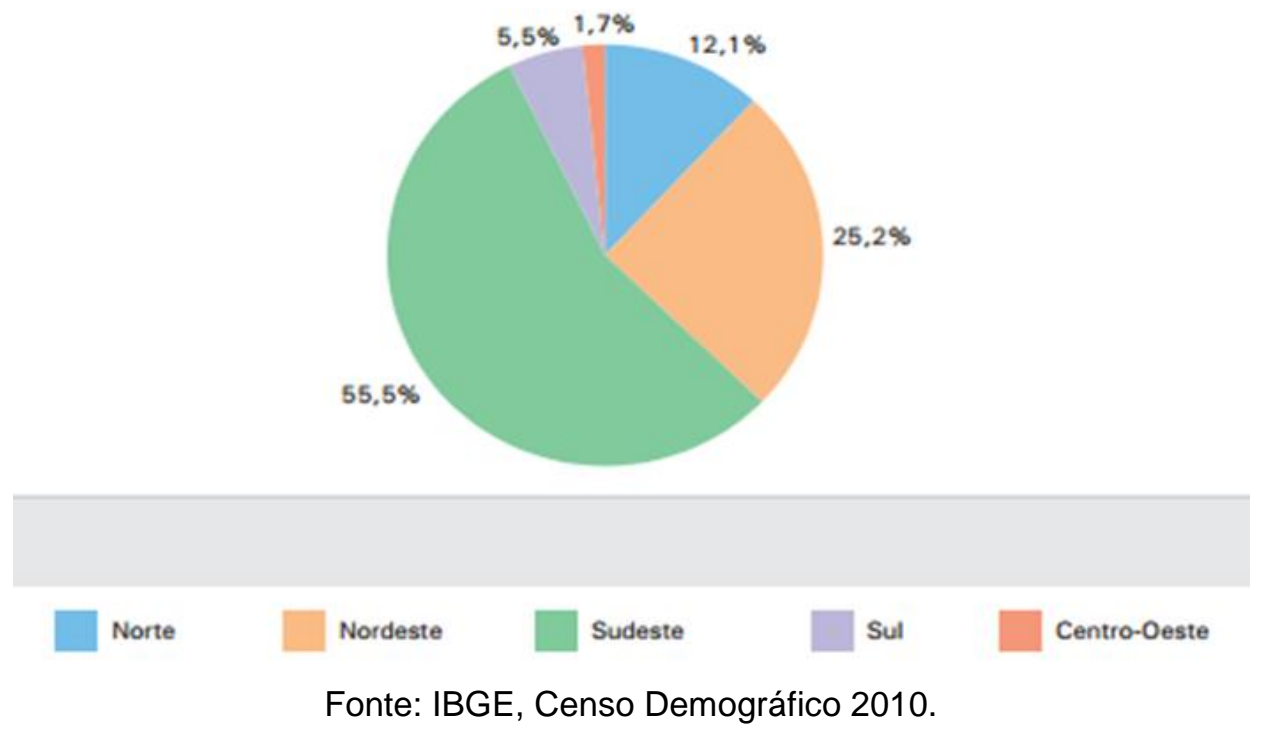

Em face dos dados apresentados pelo Censo IBGE 2010, ilustrando a distribuição dos assentamentos precários por região do país, como também, a partir de diversas pesquisa relacionadas ao processo de produção das cidades, nota-se, que ainda persiste o desequilíbrio no processo de ocupação do espaço urbano, o que pode muitas vezes, ser atribuído às interferências de agentes especulativos inescrupulosos que ao prevaleceram sobre a função social do solo, continuam assinalando as diferenças marcantes na paisagem das cidades, contribuindo ainda, para o processo de indução dos assentamentos precários (loteamento ilegal ou clandestino, favelas, cortiços) associados à auto-produção de moradia, que a princípio se constituiu como única opção de residência para a população migrante instalar-se nos grandes centros urbanos do país. 


\section{stom}

Gráfico 02 - Domicílios particulares ocupados em setores censitários de aglomerados subnormais, por características e localização predominantes do sítio urbano - Brasil - 2010.

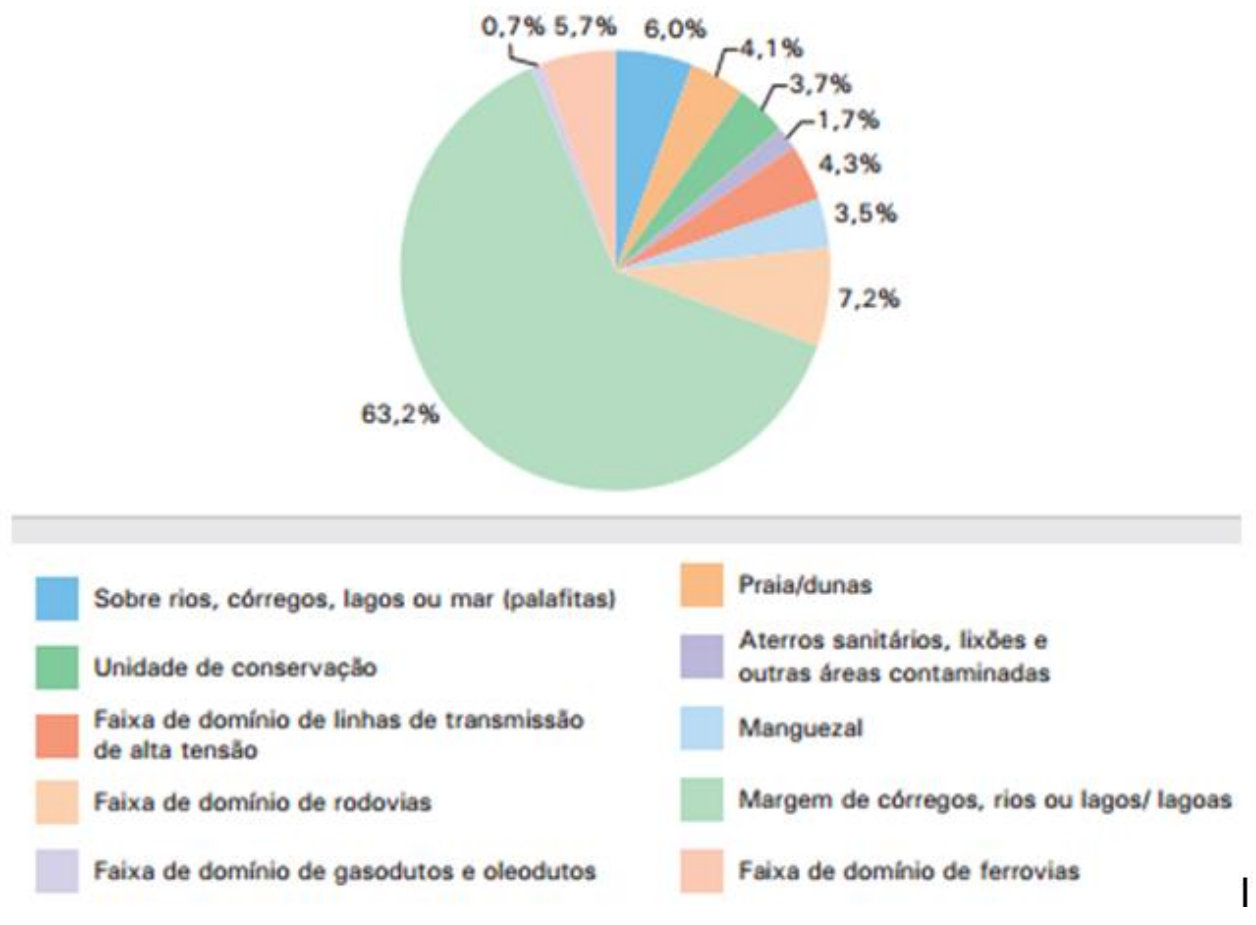

Fonte: IBGE, Censo Demográfico 2010.

O contexto apresentado na figura acima, não se constitui em fatos novos, apenas confirmam as características do padrão de urbanização presentes num porcentual significativo das cidades brasileiras. Trata-se de uma questão de extrema importância, se constituindo numa temática, que vem ao longo de décadas, sendo analisada por diversas áreas do conhecimento.

Desse modo, Edésio Fernandes (2004), ao estudar esse tema, identificou os agentes que contribuem no processo de informalidade, elencando:

[...] a carência de opções de moradias adequadas e acessíveis para os grupos mais pobres, devido à ação de mercados especulativos e informais; os sistemas políticos clientelistas; bem como o padrão de planejamento elitista e tecnocrático, baseado em critérios técnicos ideais, mas que não expressam a realidade socioeconômica de produção e de acesso à terra urbana (FERNANDES, 2004, p.245-246). 
Esse contexto também é encontrado nas análises efetuadas por Tomás Moreira (2002) a respeito do processo de urbanização das cidades brasileiras que, em seu ponto de vista, abarcam uma série de problemas:

Contudo, a realidade brasileira, calcada numa situação de extrema exclusão social a partir de uma desigualdade aviltante na distribuição de rendas, do descaso do Poder Público, notadamente, com a especulação imobiliária, de uma legislação por muito tempo elitista, de ausência de políticas públicas, habitacional e urbana eficientes, os assentamentos urbanos informais aparecem como alternativa de acesso à moradia a população de baixa renda, que (sobre) vive em condições absolutamente indignas, em áreas insalubres e, muitas vezes, de risco. De tudo isso, se pode dizer que a especulação imobiliária é o fator mais difícil de erradicar 'que resiste até hoje e molda a estrutura do espaço urbano', evidenciando que ainda há uma submissão muito forte da terra ou capital (MOREIRA, 2002. p.08).

O resultado dessa pífia atuação do poder público gera uma situação deplorável de desigualdade e exclusão social, intensificando o processo de segregação e o grave isolamento dos grupos sociais. Esse quadro, presente no cotidiano de muitas cidades brasileiras, é notadamente caracterizado por diversos aspectos: deterioração do espaço urbano; escassez da oferta de moradias, provocando ocupações irregulares em áreas de risco ambiental juridicamente protegidas; ausência de infraestrutura física como saneamento básico, sistema viário, sistema de transporte coletivo; e ausência de infraestrutura social, compreendida como sistema de saúde, educação, esporte e lazer.

Em face do exposto, Sheehan (2003) salienta que apesar dos avanços tecnológicos e avanços sociais, as cidades ainda são locais de exclusão e segregação socioambiental.

Séculos de inovações tecnológicas e avanço social, pouco fizeram para fechar essa fenda [sócio-ambiental]. Sem condições de disputar o mercado imobiliário 'legal', centenas de milhões de pessoas buscam abrigo nos locais mais precários, em encostas íngremes ou várzeas, vivendo não apenas sob ameaça constante de despejo, mas também em áreas mais vulneráveis a desastres naturais, poluição e doenças causadas por falta de abastecimento de água e saneamento básico (SHEEHAN, 2003, p.148).

Mediante as proposituras de Sheehan (2003), a urbanização acelerada e o processo de industrialização tardia foram os fatores determinantes para a constituição da precariedade (quadros deploráveis) presente nos espaços urbanos, onde as demandas socioambientais se multiplicaram frente às limitadas intervenções do poder público. Tais apontamentos enfocam o difícil reconhecimento da questão urbana, tendo em vista a dificuldade, ao longo dos anos, da 
implementação de políticas públicas aptas em atender as amplas necessidades dos diversos setores: habitacional, de saneamento, de transporte e mobilidade urbana, dentre outros. Assim, nem mesmo o vertiginoso crescimento das cidades e o agravamento dos problemas sociais, urbanos e ambientais, fizeram com que estas fossem vistas como essenciais para 0 desenvolvimento do país. Outro aspecto, refere-se à questão fundiária, onde a existência de vazios urbanos acabaram contribuindo para o aumento de custos de manutenção de áreas servidas por infraestrutura em condições ociosas devido ao espraiamento horizontal das cidades.

Sem desmerecer as diversas abordagens relacionadas a cidade, não se pode deixar de considerá-la como reflexo das condições macroeconômicas. Algumas características estruturais no sistema urbano de nossas cidades são elementos centrais, como a concentração e irregularidade na estrutura fundiária, onde há uma alta concentração de propriedade e uma imensa irregularidade na apropriação e uso da terra. Para vários autores, entre eles Flávio Villaça (1998) e Henri Ascerald (2009) a análise do espaço urbano, sobretudo nos grandes centros, identifica como aspecto marcante a discrepância dos usos residenciais conforme o perfil socioeconômico da população residente, o que comumente é denominado de segregação socioespacial, produzida a partir de uma dinâmica desconexa, que se mostra na guetificação da elite - morando em condomínios residenciais fechados com confortos que transcendem os limites urbanísticos máximos, e na concentração informal de população de menor poder aquisitivo, vivendo em áreas inadequadas e muitas vezes, desprovidas do mínimo existencial, totalmente a margem da legislação vigente.

Figura 01: Henri Acserald (2009): segregação residencial sustentada pelo mercado de terras seria a condição da reprodução dos impactos ambientais. A precariedade habitacional é uma problemática socioambiental. 


\section{Stom Fórum Ambiental}

da Alta Paulista
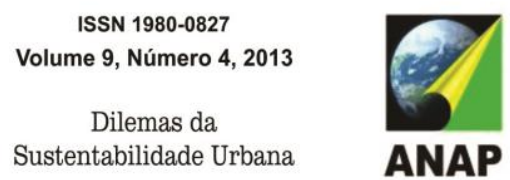

ANAP
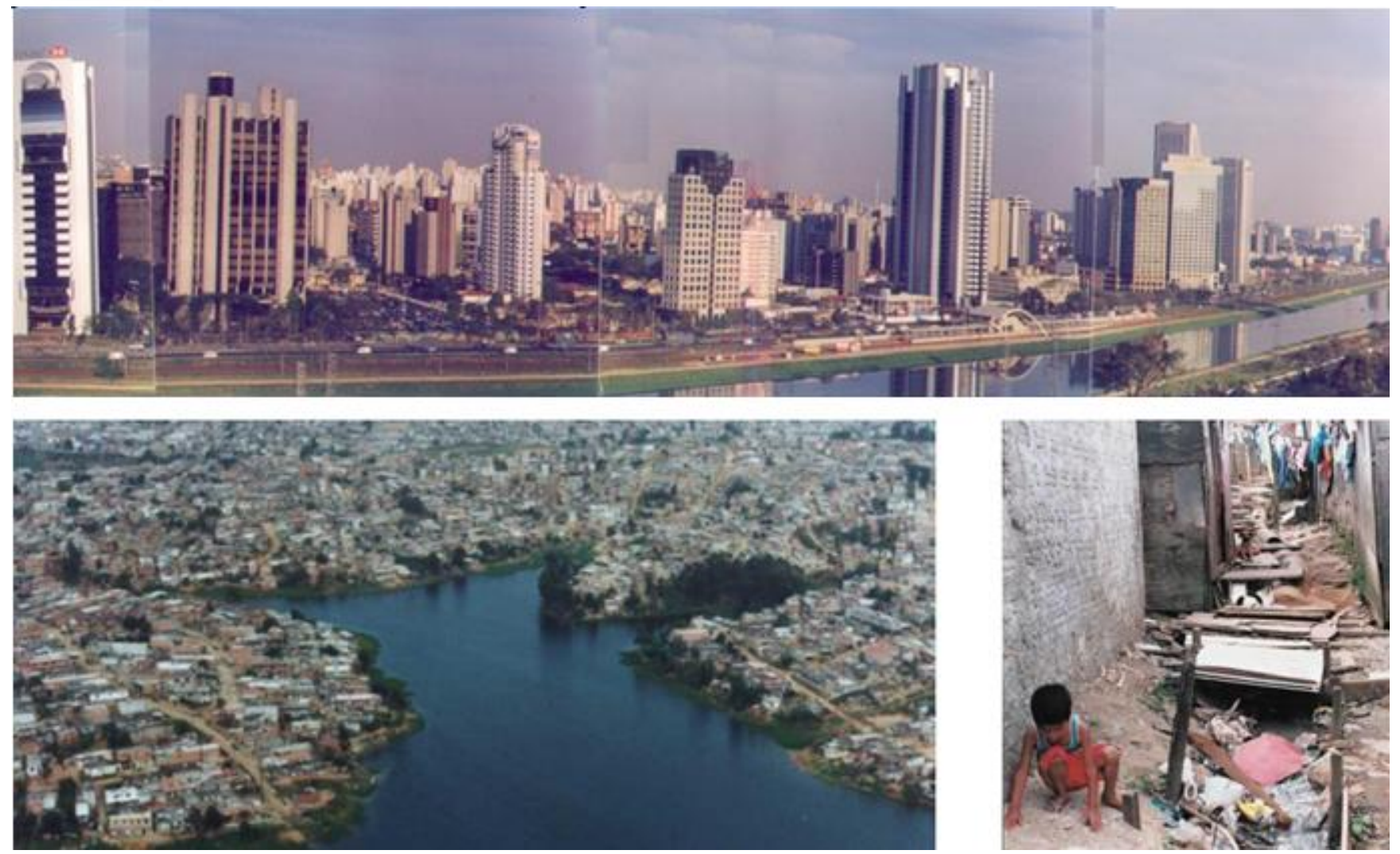

Fonte: http://eneeamb.com.br/webroot/upload/extras/extras-561023863.pdf

Diante dos cenários apresentados na Figura 01, é possível não somente identificar, como também dimensionar os efeitos produzidos pela lógica da especulação imobiliária urbana, onde comumente nos quadros de maior gravidade encontramos famílias de menor renda ou sem renda, ocupando regiões periféricas, desvalorizadas, como por exemplo: áreas insalubres nas proximidades de parques industriais, assim como os fundos de vales, margens de córregos, áreas de encostas, dentre outras localidades.

Como uma das faces da informalidade urbana, têm-se as favelas, caracterizadas pelas ocupações espontâneas (invasões) promovidas pela população de menor poder aquisitivo, em vazios urbanos privados (glebas e terrenos vagos, podendo ser inclusive em APP) ou públicos (áreas afetadas de uso comum ou bens de uso especial).

A ocupação de localizações sem pagar por elas - as chamadas 'invasões' - tem eventualmente facilitado às classes populares um pouco do usufruto das vantagens do privilegiado espaço produzido pela alta renda. Um pouco apenas, pois na verdade há um preço a ser pago pelas vantagens desse espaço, um preço que tais classes não podem pagar. Elas não podem usufruir as vantagens do sistema viário, cada vez mais produzido para o automóvel, o comércio e os 


\section{stom}

serviços. Usufruem principalmente a proximidade ao subemprego (VILLAÇA, 2001, p.225).

O loteamento clandestino, como no caso da favela, tem sua morfologia definida pela localização, natureza do sítio e pelas barreiras naturais e artificiais. Duarte, Silva e Brasileiro (1996) explicam que há outros elementos que podem vir a caracterizar a morfologia das favelas, como por exemplo:

[...] tamanho (desde o pequeno nucleamento até as grandes aglomerações); situação fundiária (áreas públicas, áreas privadas e áreas devolutas); tempo de ocupação (recente, consolidada, em fase de consolidação); processo de ocupação (resultante de invasão organizada ou espontânea), terminando de influir no padrão da ocupação (ordenada, irregular, linear) (DUARTE; SILVA; BRASILEIRO, 1996, p.45).

As feições desses assentamentos rompem a linearidade da paisagem urbana, ressaltando as diferenças entre a cidade formal e informal.

Assim como as outras interfaces da cidade, a favela é controlada por um mercado de terras que dita regras para uso e ocupação desses espaços, viabilizando as relações formais, ora informais, de aluguel, venda, revenda, transferência e cessão. Rolnik (1997, p. 14) esclarece que este mercado de terra é viabilizado por uma "operação de 'desmonte' da legislação urbanística", a qual, via de regra, favorece os especuladores imobiliários, tanto no aspecto político, como financeiro. Bueno e Reydon (2006) apontam que o Estado é responsável por esse "descontrole urbanístico" nas cidades.

Os descontroles urbanísticos, promovidos pelos assentamentos das populações de baixa renda, constituíram um verdadeiro laissez-faire, que foi instituído pelo Estado na medida em que este, até os dias atuais, não oferece um aparato institucional de controle do solo urbano e permite que seja construído um enorme território sem seu controle (BUENO; REYDON, 2006, p.409).

Bueno e Reydon (2006, p.404) enfatizam que a contradição presente na atual legislação urbanística promove segregação e a exclusão social na cidade ilegal, visto que essa "lei desobriga o estado de estender as benfeitorias públicas, já que os assentamentos populares não obedecem à legislação". Desse modo, em razão da conivência e omissão do Estado, os assentamentos precários nas suas diferentes manifestações, acaba se consolidando nas franjas da cidade, carente de infraestrutura básica, equipamentos e serviços públicos, e o que é muito pior, intensificando a pobreza urbana. 
Swyngedouw (2001, p.84) considera que a cidade, a sociedade e a natureza, são representações "inseparáveis, mutuamente integradas, infinitamente ligadas e simultâneas", responsáveis pelas "contradições, tensões e conflitos". Segundo Braga (2003) essa nova conjuntura apresentada por Swyngedouw (2001), faz parte da dinâmica das cidades, como por exemplo, os conflitos sócio-ambientais decorrentes do parcelamento do solo urbano.

[...] o avanço da urbanização sobre o meio natural, de maneira desordenada, tem causado a degradação progressivas das áreas de mananciais remanescentes, com a implantação de loteamentos irregulares e a instalação de usos e índices de ocupação incompatíveis com a capacidade de suporte do meio. O parcelamento indiscriminado do solo nas periferias urbanas é uma das principais fontes de problemas ambientais das cidades (BRAGA, 2003, p.113).

Segundo Braga (2003, p.114-115) essas ocupações em áreas de mananciais são apenas parte do problema, pois as "alterações decorrentes do uso do solo, como a retirada da vegetação [...] e a impermeabilização do solo [...], causam um dos impactos humanos mais significativos no ciclo hidrológico", como por exemplo, os problemas de drenagem urbana, presente em quase todas as cidades brasileiras.

No âmbito da questão, não se pode ignorar, por exemplo, o impacto econômico de gigantescas ocupações ilegais e precárias ocorridas no território urbano, que além de colocarem em risco mananciais de água potável - tendo em vista o alto custo do tratamento da água crescentemente poluída e o alto custo de buscar fontes de água em bacias sempre mais distantes, contribuem também, para a ocorrência de acidentes ambientais.

Especificamente nos espaços considerados como de risco, os efeitos desses eventos são, via de regra, assustadores, pois podem afetar drasticamente o desenvolvimento de uma dada região, assim como a infraestrutura física e social, e sobretudo, a saúde humana ao tirar a esperança e até mesmo a vida de um número cada vez maior de pessoas, quando não de toda uma comunidade.

Para o Ministério da Saúde (2002) - Programa Nacional de Vigilância em Saúde Ambiental dos Riscos Decorrentes dos Desastres Naturais, muitos são os fatores que contribuem para esse contexto, dentre eles, podem ser apontados:

[...] as mudanças climáticas globais, o aquecimento global e uma crescente vulnerabilidade das comunidades, provocada pela urbanização generalizada, a degradação do meio ambiente causada pelo manejo inadequado dos recursos 
naturais, a contaminação ambiental, a política pública ineficiente e o baixo investimento em infra-estrutura (MINISTÉRIO DA SAÚDE, 2002, p.8).

Os estudos realizados por Marcelino (2008, p.17), evidenciaram não apenas, a gravidade desses eventos, mas essencialmente suas nuances, ao afirmar que no Brasil a distribuição dos desastres naturais "está mais associada às características geoambientais do que as socioeconômicas, uma vez que as áreas de favela, os bolsões de pobreza e a falta de planejamento urbano estão presentes na maioria das cidades brasileiras".

$\mathrm{Na}$ realidade, muitos desses eventos são decorrentes do processo de ocupação irregular em regiões de alta vulnerabilidade ambiental. Em grande parte das situações, os próprios ocupantes ao modificarem as condições físicas do local, seja nos morros ou nas várzeas, buscando eliminar as "inadequações naturais" acabam por realizar uma ocupação predatória, que tem, ao longo dos anos, contribuído para a ocorrência de acidentes de diversas ordens, tais como os deslizamentos de encostas, as enchentes e inundações.

Essas localidades, em regra, não oferecem condições mínimas de habitabilidade e infraestrutura básica à boa parte dos seus habitantes, ou seja, os mesmos não têm acesso aos serviços públicos e vivem em situação de alta vulnerabilidade socioambiental ${ }^{3}$, decorrentes da inadequada e incipiente estrutura existente em assentamentos e construções precárias.

$\mathrm{Na}$ literatura, a dimensão ambiental, via de regra, surge também quando o estudo se refere aos processos de regularização de assentamentos precários consolidados em áreas de preservação permanente. Estas áreas, por serem caracterizadas como de fragilidade ambiental, são constitucionalmente protegidas e inadequadas para o parcelamento de solo. Entretanto, em razão de sua importância, essa dimensão deveria ser sempre atendida em qualquer contexto em que se faça necessário a implementação dos processos de regularização, tendo em vista que, independente de sua localização - inseridos parcial ou totalmente em áreas de fragilidade ambiental - todo assentamento regular ou não tem implicações ambientais, pois o próprio processo de ocupação gera impacto ambiental, além do que são fontes produtoras de resíduos

\footnotetext{
${ }^{3}$ Vulnerabilidade socioambiental: "associação de exposição a riscos e perturbações provocadas por eventos ou mudanças econômicas e exposição a riscos ambientais e precariedade de acesso a serviços públicos" (Alves, 2006)

Segundo Denaldo, R (2013), São Paulo conta com 29,2\% da população, totalizando 3 milhões de pessoas, encontra-se em patamares de alta vulnerabilidade social, sendo 10,9\% (331 mil pessoas) mora em áreas com alta vulnerabilidade ambiental, com baixa cobertura de esgoto e próximo às margens de cursos d'àgua, e $70 \%$ dessas pessoas reside em setores subnormais.
} 
de diversas naturezas e muitas vezes não contam com infraestrutura mínima e prestação de serviços públicos essenciais, colocando em risco a sustentabilidade desses espaços.

Porém, se faz necessário considerar que a dimensão ambiental começou a ser discutida nos programas de regularização somente no final da década de 90 , em razão das proporções gigantescas dos assentamentos precários instalados em áreas protegidas e da dificuldade de viabilização dos mesmos.

Em que pese, o contexto apresentado por esses apontamentos, assim como os recentes dados publicados por diversos órgãos governamentais (Figura 02 e 03), para além de reafirmarem a grave crise encontrada em parte significativa das cidades brasileiras, evidenciam a premência de adoção de novos paradigmas de planejamento e gestão das cidades, notadamente no que se refere à questão do Direito à Cidade, que deverá ser implementado por meio de políticas públicas capazes de oferecer respostas às demandas por padrões sustentáveis de vida em áreas urbanizadas.

Figura 02: Mapa de distribuição dos aglomerados subnormais no País - 2010.

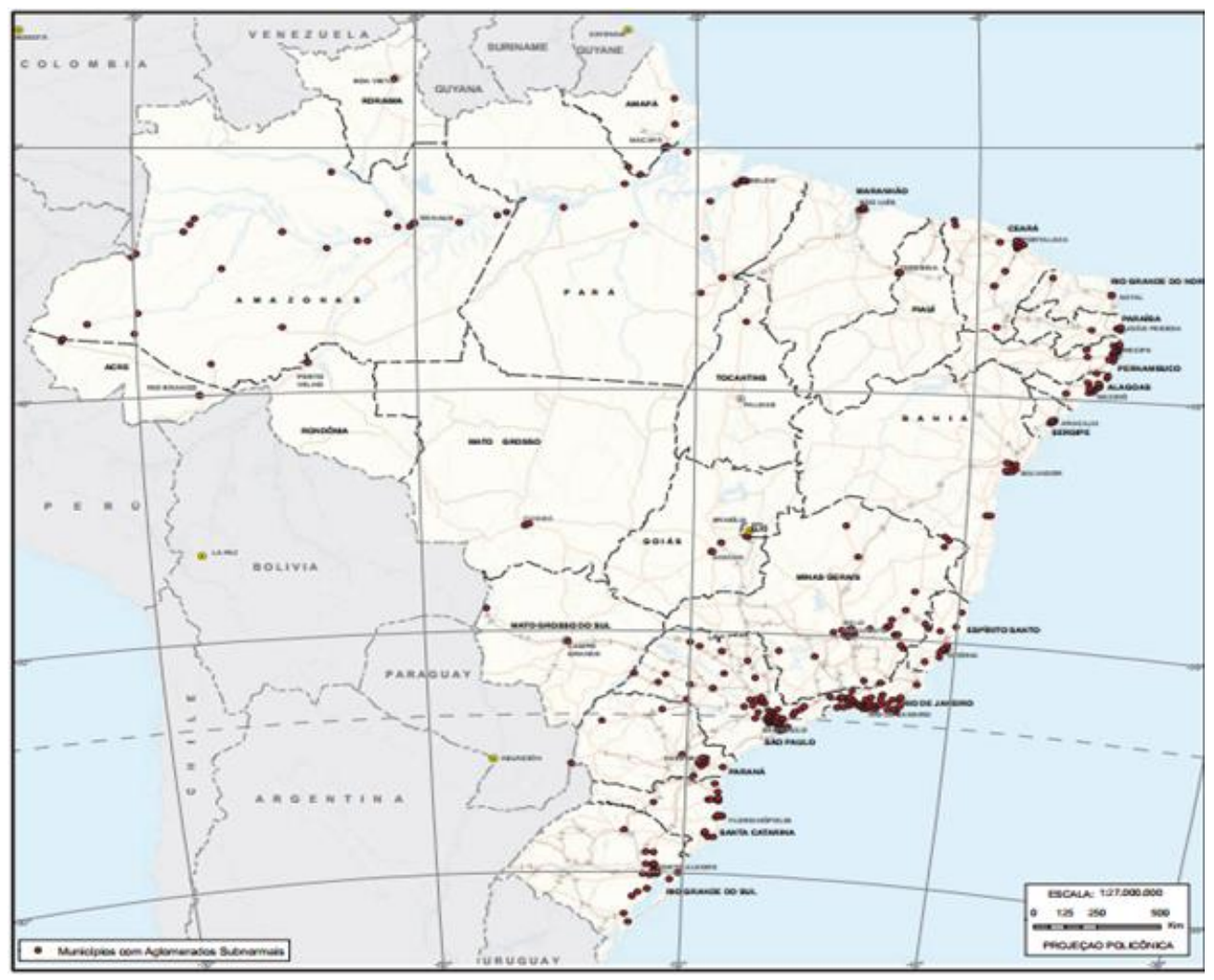

Fonte: IBGE, Censo Demográfico 2010. 
Figura 03: Assentamentos precários em áreas ambientalmente sensíveis: dimensão do problema.

\author{
Brasil: 12,4 milhões de pessoas em \\ assentamentos precários - $14 \%$ da \\ população total; (CEM-CEBRAP, 2007) \\ Concentração em RMs \\ RMs: $20 \%$ no Rio de Janeiro; $22 \%$ em \\ São Paulo; $20 \%$ em Belo Horizonte; \\ 13,3\% em Goiânia; $30 \%$ em Salvador; \\ 46\% em Recife; e $31 \%$ em Fortaleza \\ (Maricato, 2001). \\ RMSP: 2,16 milhões de pessoas \\ (IBGE, 2010) \\ Muitos assentamentos se localizam \\ em áreas ambientalmente sensíveis.
}

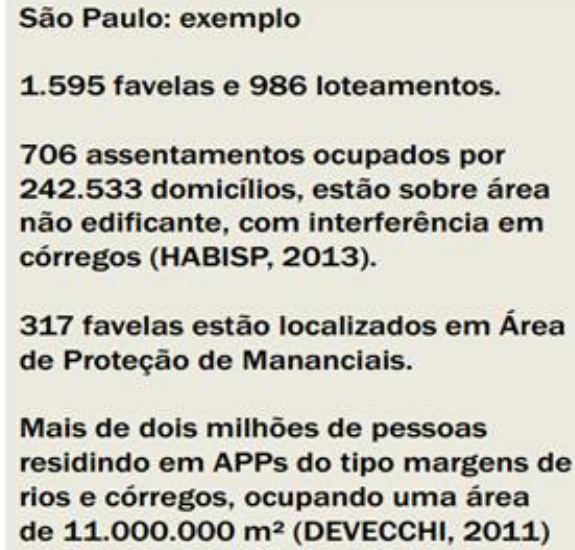

317 favelas estão localizados em Área de Proteção de Mananciais.

Mais de dois milhões de pessoas residindo em APPs do tipo margens de rios e córregos, ocupando uma área de $11.000 .000 \mathrm{~m}^{2}$ (DEVECCHI, 2011)

Fonte: http://eneeamb.com.br/webroot/upload/extras/extras-561023863.pdf

Os dados apresentados na pesquisa CEM-CEBRAP/2007 e IBGE /2010 ilustram que a produção desses espaços durante as últimas décadas do século $X X$ aumentou ignorando a previsão legal. Entretanto, a localização destes assentamentos se configura como agravante de maior complexidade, tendo em vista sua grande incidência em áreas de encostas, de mananciais e em margens de corpos d' água, submetendo a população ocupante a riscos naturais de toda ordem, os quais podem ser observados nos cenários urbanos retratados na figura 04. 


\section{The Fórum Ambiental}

da Alta Paulista
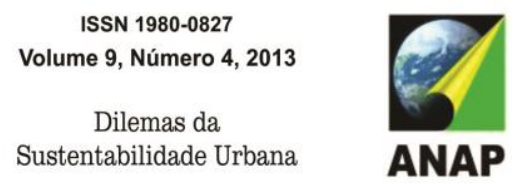

ANAP

Figura 04: Expansão Urbana e degradação dos corpos d'água.

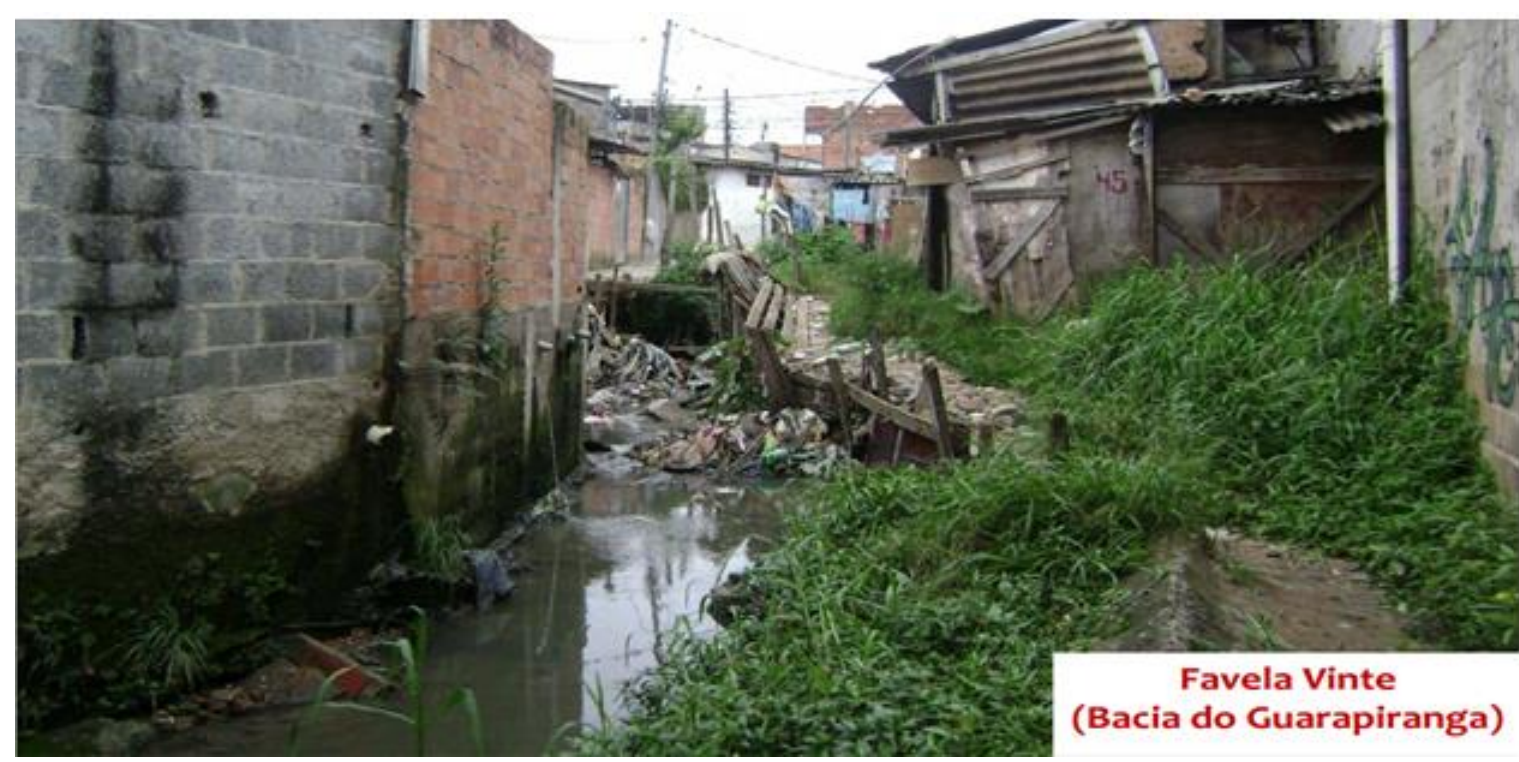

Fonte: http://siteresources.worldbank.org/INTLAC/Resources/257803-1351801841279/AmauriPollachi_pdf

A partir deste contexto, os assentamentos informais localizados em áreas ambientalmente vulneráveis, passaram a se constituir num aspecto que vai muito além da delicada problemática urbana, tendo em vista a complexidade das questões de ordem jurídica, social, econômica, cultural, e principalmente urbanística, decorrentes da longa ausência do Estado frente à questão. Desse modo, foi de extrema relevância a proposição de novos mecanismos jurídico-urbanísticos potencializados para o enfrentamento desse enorme desafio.

Certamente, a promulgação do Estatuto da Cidade se constituiu, no primeiro passo visando à reversão da informalidade urbana, tendo em vista que a Lei Federal 10.257/01 previu um rol de instrumentos voltados para a questão da Regularização Fundiária a serem aplicados por meio da política de desenvolvimento urbano. Diante de tais propósitos, recentemente foram propostos novos caminhos de atuação para o enfrentamento da questão, iniciado pela nova abordagem resultante da evolução conceitual do termo de Regularização Fundiária e, principalmente pela adoção de novos mecanismos para trabalhar com essa complexidade

O novo sistema jurídico e institucional que passa a reger as políticas urbanas em suas diversas faces, inclusive em ações de proteção ambiental, possibilita uma nova abordagem da questão dos assentamentos precários, tendo em vista que sua grande incidência ocorre em áreas de vulnerabilidade ambiental, protegidas tanto pela legislação federal como estadual. 
Neste sentido, a elaboração de políticas públicas compromissadas na reversão do cenário apresentado, deverá ser pautada por uma visão integrada, por meio de mecanismos inovadores e convergentes, que tenham por fim contemplar a adequada organização do espaço urbano e a tutela ambiental como funções primordiais e complementares, condições essas fundamentais para a garantia da qualidade de vida nos espaços urbanizados.

Não há duvidas de que, os cenários apresentados pelas cidades no país, desde as de menor porte e essencialmente aquelas inseridas em áreas metropolitanas, clamam pela incorporação de práticas inovadoras específicas ao planejamento urbano ambiental, bem como do projeto urbano.

Com esse imenso compromisso, busca-se no projeto urbano a possibilidade de incorporação de novos paradigmas, onde seja possível a priorização da qualidade de vida num contexto amplo da dinâmica urbana, por meio da conjugação dos princípios sustentáveis e da resiliência do ambiente construído, em busca de possíveis alternativas potencializadas em mitigar ou reverter as gigantescas demandas da cidade contemporânea.

\section{CONSIDERAÇÕES FINAIS}

Nas cidades brasileiras, muitos são os fatores que provocaram a ocorrência de assentamentos precários em áreas de vulnerabilidade ambiental - as APPs, entre os quais são evidenciados a carência habitacional, disponibilidade de espaços com restrição ambiental, desrespeito as normas ambientais e urbanísticas, a ausência de fiscalização dos órgãos responsáveis, a inescrupulosa especulação imobiliária e, sobretudo o descaso do poder público. Essas localidades, em regra, não oferecem condições mínimas de habitabilidade e infraestrutura básica à boa parte dos seus habitantes, ou seja, os mesmos não têm acesso aos serviços públicos e vivem em situação de alta vulnerabilidade socioambiental, decorrentes da inadequada e incipiente estrutura existente em assentamentos e construções precárias.

A partir desse cenário, os efeitos decorrentes do intenso processo de crescimento urbano, aliados a uma arcaica sistemática de políticas públicas incipientes e desconexas, acabaram por assinalar as diferenças marcantes na paisagem das cidades, as quais encontram expressividade nos quadros crescentes de segregação e desigualdade socioespacial. Diante de tais cenários, recentemente foram propostos novos caminhos de atuação para o enfrentamento da questão, iniciado pela nova abordagem resultante da evolução conceitual do termo de 
Regularização Fundiária e, principalmente pela adoção de novos mecanismos para trabalhar com essa complexidade. Desse modo, foi de extrema relevância a proposição de novos mecanismos jurídico-urbanísticos potencializados para o enfrentamento desse enorme desafio. Neste sentido, a elaboração de políticas públicas compromissadas na reversão do cenário apresentado, deverá ser pautada por uma visão integrada, por meio de mecanismos inovadores e convergentes, que tenham por fim contemplar a adequada organização do espaço urbano e a tutela ambiental como funções primordiais e complementares, condições essas fundamentais para a garantia da qualidade de vida nos espaços urbanizados.

\section{REFERENCIAS}

ACSELRAD, Henri. Discursos da Sustentabilidade Urbana. Revista Brasileira de Estudos Urbanos e Regionais, Campinas: no 01, maio/ 1999.

ALFONSIN, Jaques Távora. Do "diga que não estou" à relação entre pobreza e função social da terra no Brasil. In: FERNANDES, E.; ALFONSIN, B. Direito Urbanístico: Estudos Brasileiros e Internacionais. Belo Horizonte: Del Rey, 2006.

BALBIM, Renato. Avanços Recentes no Quadro Normativo Federal da Regularização Fundiária. 2010. Disponível em: < http://www.ipea.gov.br/ppp/index.php/PPP/article/viewFile/176/189>. Acesso em: 04 Março 2011.

BRAGA, Roberto. Qualidade de vida urbana e cidadania. Território \& Cidadania. Rio Claro, SP, ano II, $\quad \mathrm{n}$ - 2, jun-dez, $2002 . \quad$ Disponível em: <http://www.rc.unesp.br/igce/planejamento/territorioecidadania/Artigos/Braga\%203.htm> 09 jan. 2009.

BRASIL. Constituição (1988). Constituição da República Federativa do Brasil: promulgada em 5 de outubro de 1988. . São Paulo: Revista dos Tribunais, 2009.

17.07.2001.

. Lei Federal no 10.257 (2001). Estatuto da Cidade. DOU 11.07.2001, ret. DOU

Prevenção de riscos de deslizamentos em encostas: guia para elaboração de políticas municipais / Celso Santos Carvalho e Thiago Galvão (orgs). Brasília: Ministério das Cidades; Cities Alliance, 2006. 111 p.

. Resolução CONAMA № 369, de 28 de março de 2006. 


\section{Them

CHAUÍ, Marilena. O que é ideologia. São Paulo: Brasiliense, 1984.

CAMPO, Pedro Abramo. A dinâmica imobiliária. Elementos para o entendimento da espacialidade urbana. In: Cadernos IPPUR/UFRJ, ano III, n. especial, dez. 1989. Rio de Janeiro: UFRJ, 1989. pp. 47-70.

CASTELlO, Lineu. A Percepção em Análises Ambientais. Percepção Ambiental - A Experiência Brasileira, São Carlos, Editora da UFSCAR, 1996.

DAVIS, MikeDavis. Planeta Favela.Sao Paulo, Boitempo, 2006.

DI PIETRO, Maria Sylvia Zanella. Bens públicos: domínio urbano: infra-estrutura. Belo Horizonte: Fórum, 2007, 360 p.

ESTATUTO DA CIDADE. Lei o 10.257, de 10 de julho de 2001, que estabelece diretrizes gerais da política urbana. Guia para implementação pelos municípios e cidadãos. Brasília: Câmara dos Deputados, Coordenação de Publicações, 2001.

FERNANDES, Edésio. Questões anteriores ao Direito Urbanístico. Belo Horizonte: PUC Minas Virtual, 2006.

Regularização de Assentamentos Informais: 0 grande desafio dos municípios, da sociedade e dos juristas brasileiros. In: ROLNIK, Raquel (org) Regularização Fundiária Plena: Referências Conceituais. Brasília: Ministério das Cidades,2007.

Regularização de Assentamentos Informais: o grande desafio dos municípios, da sociedade e dos juristas brasileiros. In: ROLNIK, Raquel et. al. (coord.). Regularização Fundiária de Assentamentos Informais Urbanos. Belo Horizonte: PUC Minas Virtual, 2006.

FIGUEIREDO, Guilherme José Purvin. A propriedade no Direito Ambiental. Rio de Janeiro: Esplanada, 2004.

FIORILLO, Celso Antonio Pacheco. Curso de Direito Ambiental Brasileiro. 4ª ed. São Paulo: Saraiva, 2003.

GROSTEIN, M. D. Metrópole e Expansão Urbana: a Persistência de Processos "Insustentáveis". São Paulo em Perspectiva. Fundação SEADE. № 01, 2001.

GUIMARÃES, Solange T. de Lima. Nas Trilhas da Qualidade: algumas idéias, visões e conceitos sobre qualidade ambiental e de vida..., Revista GEOSUL, UFSC, Florianópolis, n.40, 


\section{stom Fórum Ambiental}

da Alta Paulista

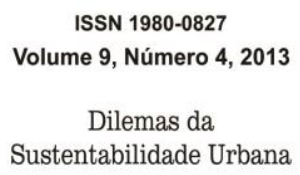

Sustentabilidade Urbana

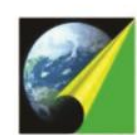

ANAP

p.

7-26,

jul./dez.

2005 ,

Disponível

em:

<http://www.cultiva.org.br/pdf/qualidade_ambiental_e_da_vida.pdf> Acesso em: 15 jan. 2009.

IBGE (Instituto Brasileiro de Geografia e Estatística). Censo Demográfico de 2000. Disponível em: <http://www.ibge.gov.br> Acesso em: 20 fev. 2009.

LIRA, Ricardo Pereira. Elementos de Direito Urbanístico. Rio de Janeiro: Renovar, 1997.

LEFEBVRE, Henri. O Direito a Cidade. Sao Paulo: Centauro, 2008.

LÜDKE, Menga; ANDRÉ, Marli E. D. A. Pesquisa em educação: abordagem qualitativa. São Paulo: EPU, 1986, 99 p.

MANCUSO, Rodolfo de Camargo. Comentário ao Código de Proteção ao Consumidor. São Paulo: Saraiva, 1991, p.275.

MARICATO, Erminia T.M. Metropole da Periferia do Capitalismo: ilegalidade, desigualdade e violência. Sao Paulo: Hucitec,1996.

MARTINS, Maria Lucia Refinetti. Moradia e Mananciais: tensão e dialogo na metrópole. Sao Paulo: FAU-USP/FAPESP, 2006, 206p.

MAZETTO, Francisco de Assis Penteado. Qualidade de vida, qualidade ambiental e meio ambiente urbano: breve comparação de conceitos. Sociedade \& Natureza, Uberlândia, v. 14, n.24, p. 21-31, jun./dez. 2000.

MINISTÉRIO DAS CIDADES. Planos de Habitação de Interesse Social. PLHIS - Módulo 2 Diagnóstico, Necessidades Habitacionais. Secretaria Nacional da Habitação, 2007.

MORAES, Lúcia; DAYRELL, Marcelo. Direito Humano à Moradia e Terra Urbana. Curitiba: INESC, 2008.

PIRES, Luis Manuel Fonseca. Loteamentos Urbanos: natureza jurídica. São Paulo: Quartier Latin, 2006, $160 \mathrm{p}$.

PISSOL, Kátia Maria Santos de Andrade. A Dinâmica Urbana: Uma Leitura da Cidade e da Qualidade de Vida no Urbano. Caminhos de Geografia, Uberlândia - MG, v. 7, n. 17, p. 1-7, fev. 2006, ISSN: 1678-6343. Disponível em: $<$ http://www.caminhosdegeografia.ig.ufu.br/viewarticle.php?id=25\&layout=abstract> Acesso em: 10 jan. 2009

RICHARDSON, P. G.. Piaget: teoria e práticas. São Paulo: Ibrasa, 1981. 
ROLNIK, Raquel. Planejamento Urbano nos Anos 90: Novas Perspectivas para Velhos Temas. RIBIERO; QUEIROZ, Luiz César; SANTOS JUNIOR, Orlando Alves (Orgs.). Globalização, Fragmentação e Reforma Urbana. Rio de Janeiro: Civilização Brasileira: 1997, p. 351-360.

ROSSET, Franciele. Procedimentos metodológicos para estimativa do índice de áreas verdes públicas. Estudo de caso: Erichim, RS. 2005. 60 p. Dissertação (Mestrado) Universidade de São Carlos, São Carlos, 2005. Disponível em: <http://www.bdtd.ufscar.br/tde_busca/arquivo.php?codArquivo=631>. Acesso em: 7 jan. 2009.

SAULE JUNIOR, Nelson. O Direito à moradia como responsabilidade do Estado Brasileiro. In. Caderno de Pesquisa do CEBRAP - Centro Brasileiro de Análises e Planejamento, n. 7, maio 1997.

- Estatuto da Cidade: Instrumento de reforma Urbana. [on-line] Disponível em<http://www.estatutodacidade.org.br/estatuto/artigos.shtml>. Acesso em 20 de abril de 2005.

SAULE JÚNIOR, Nelson (org.). Direito Urbanístico: Vias jurídicas das políticas urbanas. Porto Alegre: 2007.

SCHEID, Cintra Maria. A Regularização Fundiária dos Assentamentos Urbanos Informais como Garantia do Mínimo Existencial no Direito a Moradia, 2008. Dissertação de Mestrado. Programa de Pós-Graduação em Direito - Área de Concentração em Direitos Sociais e Políticas Públicas - Universidade de Santa Cruz, 2008.

SILVA, José Afonso da. A dignidade da pessoa humana como valor supremo da democracia. In: Revista de Direito Administrativo, Rio de Janeiro: Renovar, n. 212, abril/junho 1998.

SUNDFELD, Carlos Ari, O Estatuto da Cidade e suas Diretrizes Gerais. In: Estatuto da Cidade - Comentários a Lei Federal 10.257/01, São Paulo, Ed. Malheiros, 2002 - 1ª Edição, p. 59/60.

VILLAÇA, F. Espaço intra-urbano no Brasil. São Paulo: Nobel, 1998.

VILANI, Rodrigo Machado. O princípio de justiça social e ambiental e a eficácia do plano diretor participativo. 2002. 229 f. Tese (Doutorado em Meio Ambiente e Desenvolvimento) Universidade Federal do Paraná, 2006 